\title{
ABSORÇÃO DE CÁLCIO PELOS TECIDOS DA FOLHA DO CAFEEIRO (Coffea arabica L., var. MUNDO NOVO) *
}

\author{
A. D. Cruz \\ J. R. SARRUGe *** \\ H. P. HAAG
}

\section{RESUMO}

A absorção de cálcio pelos tecidos de folha do cafeeiro (Coffea arabica L., var. Mundo Novo) foi estudada em cortes transversais feitos na porção média do limbo foliar de amostras de folhas colhidas em plantas cultivadas em condições de campo.

O estudo teve como objetivos, caracterizar o mecanismo de absorção de cálcio e avaliar os efeitos de $\mathbf{K}, \mathbf{M g}$ e $\mathbf{B}$ na absorção daquele nutriente.

A técnica experimental padrão empregada em todos os ensaios constituiu em submeter cortes de $300 \mu$ de espessura a uma série de soluções com concentrações crescentes de cálcio, contendo $45 \mathrm{Ca}$ como traçador, luminosidade de $3000 \mathrm{lux}$, temperatura e arejamento constantes.

A série de soluções de cálcio foi constiturda das seguintes concentrações de $\mathrm{CaC1}_{2}$ :

$5 \times 10^{-6} \mathrm{M}, 10^{-5} \mathrm{M}, 2 \times 10^{-5} \mathrm{M}, 4 \times 10^{-5} \mathrm{M}, 8 \times 10^{-5} \mathrm{M}$,

$1,6 \times 10^{-4} \mathrm{M}, 3,2 \times 10^{-4} \mathrm{M}, 6,4 \times 10^{-4} \mathrm{M}, 1,28 \times 10^{-3} \mathrm{M}$

e $2,56 \times 10^{-3} \mathrm{M}$.

Os ensaios realizados foram: absorção de cálcio na fase vege. tativa e de florescimento do cafeeiro, considerados com os padrões, absorção de cálcio na presença de inibidores metabblicos $(2,4-\mathrm{DNP}$ 10-5M, borbulhamento com $\mathrm{N}_{2}$ e temperatura de 100C); absorção de cálcio na presença de $\mathbf{K C 1} 5 \times 10-3 \mathrm{M}$, $\mathrm{KC1} 10-4 \mathrm{M}, \mathbf{M g C 1}_{2} \mathbf{5} \times 10-3 \mathrm{M}$ e $\mathrm{H}_{3} \mathrm{BO}_{3} 5 \times 10-3 \mathrm{M}$.

Os resultados obtidos foram submetidos a ańlise de regressăo e comparados estatísticamente pelo teste «t».

Continua na página 106

- Parte de tese submetida, pelo primeiro autor, a F. S. A. «Luiz de Queiroz» para obtençăo do título de Doutor. Entregue para publicação em 21/05/74. Os autores agradecem a diretoria do CENA (Centro de Energia Nuclear na Agricultura) pelo auxílio recebido.

** Departamento de Solos da Faculdade de Agronomia Eliseu Maciel, Universidade Federal de Pelotas, R. G. S.

*** Departamento de Química da E. S. A. L. Q. 
Após a análise estatística, foram calculados os valores dos parâmetros $\mathrm{Km}$ e Vm, os quais demonstraram que a absorção de cálcio, pelos tecidos foliares, é metabólica e que os íns $\mathrm{K}$ e $\mathrm{B}$ provocam um efeito estimulatório, enquanto que o $\mathrm{Mg}$ tem $\mathrm{um}$ efeito inibidor de caráter não não competitivo.

\section{INTRODUÇAO}

A absorção iônica, consiste no movimento dos íons para 0 interior das células das plantas e é definida independentemente do mecanismo e do seu envolvimento com o metabolismo celular.

Muitas vezes, o termo absorção e transporte são usados indistintamente, embora este, consista num processo mais específico que compreende um movimento ativo através de uma barreira limitante.

A absorção de íons pelas raízes é apenas uma das etapas de uma série de eventos que constitui a nutrição das plantas. Os íons depois de serem absorvidos pelas raízes são conduzidos para os xilema e posteriormente para as folhas. Antes que possam participar dos processos metabólicos no interior das folhas, os íons devem ser absorvidos pelas células das mesmas. A solução proveniente do xilema, torna-se então, o substrato de nutrientes inorgânicos das células do mesofilo.

O principal problema das investigações sobre os processos de absorção pelos tecidos foliares são devido à variabilidade do ambiente iônico das células das folhas. Esta variabilidade decorre das diferenças de temperatura, da distribuição desuniforme dos íons nestes tecidos e das mudanças na velocidade de transpiração RAINZ (1968). Entretanto, estas variáveis foram eliminadas por meio das técnicas desenvolvidas por SMITH \& EPSTEIN (1958) que, empregando cortes de tecidos de folhas, tornaram possíveis os estudos de cinética de absorção iônica pelos tecidos foliares.

Apesar das técnicas acima referidas terem sido aplicadas a alguns íons, não são encontrados na literatura estudos sobre absorção de cálcio por tecidos foliares, especialmente em amostras colhidas em plantas cultivadas em condições de campo.

O presente estudo, apoiado na teoria do carregador desenvolvida por EPSTEIN \& HAGEN (1952) tem os seguintes objetivos:

- caracterizar os mecanismos de absorção, e

- determinar os efeitos do $\mathrm{K}, \mathrm{Mg}$ e $\mathrm{B}$ na absorção do cálcio pelos tecidos foliares do cafeeiro.

\section{REVISAO DA LITERATURA}

O estudo da literatura sobre absorção de nutrientes por plantas superiores, tem demonstrado que as informações existentes se referem mais 
expressivamente ao tecido radicular e são provenientes do emprego de técnicas diversas, que têm originado resultados diversos.

No que se refere particularmente à absorção de cálcio pelos tecidos foliares, os dados encontrados na literatura dizem respeito únicamente, ao efeito destes nutrientes sobre a absorção de outros elementos e sobre a permeabilidade da parede celular. Não são encontrados na literatura, trabalhos que forneçam um subsídio tecnológico básico, para o desenvolvimento de estudos ligados à absorção de cálcio pelos tecidos do mesofilo de plantas superiores.

JOHNSON \& JACKSON (1964) estudaram a absorção de cálcio por raízes destacadas de trigo (T. vulgare $L$. $c v$. «Atlas 66») e o efeito do alumínio na absorção daquele nutriente.

As raízes, depois de mantidas durante 24 horas em água desmineralizada, foram transferidas para recipientes com $\mathrm{CaCl}_{2}$ e ${ }^{45} \mathrm{Ca}$. Concluído o período de absorção, as mesmas foram lavadas durante 2 minutos com água destilada. A seguir, foram transferidas para cadinhos de porcelana, pesadas e calcinadas a $550^{\circ} \mathrm{C}$. A cinza foi dissolvida em $\mathrm{HNO}_{3}$ e alíquotas da solução resultante, foram retiradas para determinação do cálcio absorvido.

Os resultados mostraram que, nas primeiras duas horas de ensaio, a absorção não foi linear. A linearidade foi observada no período de 2 a 10 horas.

Os efeitos das condições anaeróbicas, obtidas com borbulhamento de $\mathrm{N}_{2}$ e adição DNP, foram variáveis de acordo com o tempo, concentração do inibidor e $\mathrm{pH}$.

MOORE et al. (1961), estudaram a absorção de cálcio por raízes destacadas de cevada (Hordeum vulgare, L.). As raízes eram lavadas com água destilada, centrifugadas e depois de pesadas eram transferidas para frascos contendo $\mathrm{CaBr}_{2}, \mathrm{Ca}(\mathrm{OH})_{2}$ e ${ }^{45} \mathrm{Ca}$ na temperatura de $25^{\circ} \mathrm{C}$. Foram empregadas $7 \mathrm{~g}$ de raiz por $7 \mathrm{l}$ de solução. No fim do período de absorção $(3 \mathrm{~h})$, as raízes foram lavadas novamente com água destilada, por 10 segundos.

Os autores concluiram que, a maior parte do cálcio absorvido pelas raízes de cevada, não é metabólica. A absorção do cálcio no $\mathrm{pH}$ 5,0 não foi afetada pelas temperaturas baixas e pelo DNP. A absorção de ${ }^{45} \mathrm{Ca}$ é um reflexo da troca isotópica com o $\mathrm{Ca}$ inerte, originalmente presente na raiz.

DUNLOP (1973), estudou a absorção de cálcio por raízes Hordeum vulgare L., Trifolium subterraneum L. e Phaseolus aureus Roxb. A técnica empregada foi essencialmente a preconizada por EPSTEIN (1961).

Observou o autor, que há duas fases distintas na absorção do cálcio: uma fase inicial, chamada fase de absorção (fase I) com cerca de $1 \mathrm{~h}$ de duração, e uma fase de acumulação lenta (fase II), que se desenvolve numa celocidade constante por cerca de 12 horas. 
As relações entre absorção e concentração externa de cálcio foram analisadas pelo método de Hofstee. A fase I consistiu em 2 processos de absorção de Donnan e a fase II, mostrou um único mecanismo com $\mathrm{Km}$ $=0,077 \mathrm{mN}$ e $V \mathrm{~m}=0,15 \mu$ eq $\mathrm{g}^{-1} \mathrm{~h}^{-1}$ de tecido fresco.

HANDLEY \& OVERSTREET (1961), estudaram a absorção de $\mathrm{Ca}$ e $\mathrm{Cl}$ - por secções de raízes de milho (Zea mays, L.).

As plantas foram cultivadas em $\mathrm{Ca}\left(\mathrm{NO}_{3}\right)_{2}, 0,00025 \mathrm{~N}$ e as raízes primárias foram cortadas em segmento de $0-1,8 \mathrm{~mm}, 1,8-3,8 \mathrm{~mm}, 3,8-$ $7,8 \mathrm{~mm}$ e $7,8-11,8 \mathrm{~mm}$, a partir do ápice.

Cerca de 40 segmentos, eram colocados em $500 \mathrm{ml}$ de cada $0,005 \mathrm{~N}$ a $26^{\circ} \mathrm{C}$ durante $24 \mathrm{~h}$, contendo ${ }^{45} \mathrm{Ca}$ e ${ }^{36} \mathrm{Cl}$. Concluído o período de absorção, os segmentos eram lavados com porções sucessivas de água quente.

A observação dos gráficos obtidos, relacionando tempo e absorção, mostrou que na região meristemática de $0-1,8 \mathrm{~mm}$ a absorção do $\mathrm{Ca} \mathrm{e}$ $\mathrm{Cl}$ - é não metabólica, enquanto que nas demais regiões a absorção é aparentemente metabólica.

Os autores concluiram, que a absorção de $\mathrm{Ca}$ e $\mathrm{Cl}-$ é não metabólica nas porções não vacuoladas da raiz e metabólica nas partes vacuoladas.

MAAS (1969) estudou a absorção de cálcio por raízes destacadas de milho e sua interação com lítio, sódio e potássio.

Os experimentos foram conduzidos, com segmentos do ápice de raízes primárias. Um grama de raiz, era lavada com água desmineralizada e transferida para frascos contendo $1.000 \mathrm{ml}$ de $\mathrm{CaCl}_{2}$ a $23^{\circ} \mathrm{C}$. Concluído o tempo de absorção $(24 \mathrm{~h})$, as raízes foram lavadas com água desmineralizada.

Os resultados obtidos da análise gráfica, mostraram um mecanismo

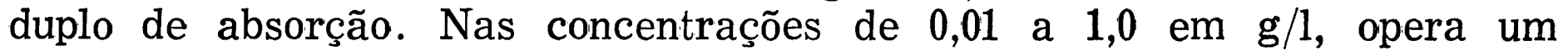
mecanismo e nas concentrações de $1,0-10,0$ em $\mathrm{g} / 1$ opera outro mecanismo em que o $\mathrm{Ca}$ é ativamente acumulado.

Os íons $\mathrm{Li}$ e $\mathrm{K}$, reduziram a absorção de $\mathrm{Ca}$, enquanto que $0 \mathrm{Na}$ mostrou um efeito intermediário.

EPSTEIN (1961), mostrou que a absorção de $\mathrm{Na}$ e $\mathrm{K}$, por raízes destacadas de cevada, é afetada pela presença de $\mathrm{Ca}$. $\mathrm{Na}$ ausência de $\mathrm{Ca}$, o $\mathrm{Na}$ interfere na absorção do $\mathrm{K}$ e o $\mathrm{K}$ na absorção do sódio. $\mathrm{Na}$ presença de $\mathrm{Ca}$, estas interferências não se verificam.

O potássio e o rubídio competem mutuamente, na presença de cálcio.

O autor concluiu, que o cálcio é essencial para o mecanismo de seletividade do processo de absorção.

SMITH \& EPSTEIN (1964), estudaram as relações entre absorção e forma do corte do tecido foliar.

Cortes de folhas do milho de $200-2.000 \mu$, foram submetidos a uma solução de $\mathrm{RbCl} 0,02 \mathrm{mM}$ a $30^{\circ} \mathrm{C}$, contendo ${ }^{86} \mathrm{Rb}$. Os resultados mostraram 
que a absorção de $\mathrm{R}$ b, por unidade peso de tecido, atinge $\mathrm{o}$ máximo no corte de $300 \mu$.

SMITH \& EPSTEIN (1964), estudaram a absorção de potássio e rubídio por tecidos foliares de milho (Zea mays L.).

Cortes de $300 \mu$ foram obtidos de folhas de milho, cultivado em solução nutritiva. Antes do início do ensaio os cortes foram lavados com $\mathrm{CaCl}_{2}$ 0,5 mM a $30^{\circ} \mathrm{C}$. O período de absorção foi de 30 minutos e foram empregados potássio e rubídio radioativos como traçadores. Concluído o período de absorção, os cortes foram lavados com solução a $9^{\circ} \mathrm{C}$ de $\mathrm{KCl}$ 5,0 $\mathrm{mM}$ e $\mathrm{CaCl}_{2}$ 0,5 $\mathrm{mM}$ durante 1 minuto.

A análise cinética dos resultados, feita pela observação dos gráficos construídos segundo o método de Leneweaver-Burk, mostrou que o isoterma de absorção, segue o modelo de Michaelis-Menten. Os autores observaram ainda, que a absorção de potássio e rubídio pelos tecidos foliares do milho é semelhante à absorção feita pelas raízes.

SMITH \& ROBINSON (1971), estudaram a absorção de sódio e potássio por cortes de folhas de laranjeiras (Citrus sinensis L.), cultivadas em condições de campo, empregando $\mathrm{Na}$ e $\mathrm{K}$ radioativos.

Os cortes do material foliar foram lavados durante $1 \mathrm{~h}$ com água desmineralizada e transferidos para as soluções experimentais contendo $\mathrm{Na}$ e $\mathrm{K}$ radioativos, por 2 horas na temperatura de $24^{\circ} \mathrm{C}$. Posteriormente, os cortes foram colocados em soluções não radioativas por 30 minutos e depois de lavados com água destilada foram pesados.

A determinação do sódio e do potássio absorvidos, foi feita pela medida da radioatividade destes elementos e os resultados calculados em microgramas de elemento absorvido por hora e por grama de tecido fresco.

Os resultados obtidos através da análise gráfica dos inversos das concentrações e velocidades de absorção, mostraram um único mecanismo de absorção para o sódio e dois para o potássio.

A absorção do sódio, foi reduzida de 20-25\% nas temperaturas baixas $\left(6^{\circ} \mathrm{C}\right)$ e na presença de DNP, enquanto que a absorção de potássio, foi reduzida de $55-60 \%$ nas mesmas condições.

ROBINSON \& SMITH (1970), mediram o influxo de ${ }^{36} \mathrm{Cl}$ por cortes de folhas de laranjeiras, cultivadas em condições de campo.

Cortes de 800-900 milimicra, foram colocados em água desmineralizada e lavados duas vezes para remover os íons das células dilaceradas. A seguir, os cortes foram mergulhados em soluções contendo ${ }^{36} \mathrm{Cl}$, durante $2 \mathrm{~h}$. Depois deste período, foram transferidos para frascos com água desmineralizada por 5 minutos, sendo posteriormente pesados e medida a radioatividade.

Os experimentos foram conduzidos na temperatura ambiente $\left(22-28^{\circ} \mathrm{C}\right)$.

Os resultados observados pelas formas das curvas obtidas, mostra- 
ram que não há evidência de dois mecanismos de absorção de $\mathrm{Cl}^{-}$e que, as formas das curvas dependem da presença de $\mathrm{Na}$ e $\mathrm{K}$. $\mathrm{O}$ influxo de $\mathrm{Cl}-$ é inibido pelo DNP e na presença de $\mathrm{N}_{2}$ e luz é mantido um certo influxo.

JACOBY \& PLESSNER (1970), estudaram a absorção de $\mathrm{Cl}^{-}$por cortes de folha e raiz de feijoeiro, cevada e milho.

Os tecidos foram colocados em erlenmeyers contendo $\mathrm{CaSO}_{4} \mathbf{0 , 2} \mathrm{nM}$ e sais contendo ${ }^{36} \mathrm{Cl}$. Os frascos com os tecidos foram incubados a $30^{\circ} \mathrm{C}$ durante $1 \mathrm{~h}$. Decorrido este período, os cortes foram lavados com $10 \mathrm{ml}$ de $\mathrm{CaSO}_{4} 10 \mathrm{mM}$.

Os resultados mostraram, que a absorção de $\mathrm{Cl}^{-}$, pelos tecidos foliares e pela raiz, tem um mecanismo múltiplo, típico de absorção ativa. Os inibidores metabólicos como DNP $5 \times 10^{-5} \mathrm{M}$ e $\mathrm{KCN} 10^{-4} \mathrm{M}$, reduzem a absorção do íon $\mathrm{Cl}^{-}$.

NISSEN (1971), estudou a absorção de sulfato, nas concentrações de $10^{-9} \mathrm{M}$ e 2,5 $\times 10^{-1} \mathrm{M}$, por raízes e cortes de folhas de cevada.

A análise cinética das isotermas foram feitas através dos valores de $\mathrm{Km}$ e $\mathrm{Vm}$.

0 autor observou que a absorção de boro pelos tecidos foliares da cana de açúcar (Saccharum officinarum L.). As plantas foram cultivadas em solução nutritiva e os cortes de $300 \mu$ retirados da porção média do limbo foliar, eram colocados em saquinhos de gaze e transferidos para as soluções de $\mathrm{H}_{3} \mathrm{BO}_{3} 0,002-40 \mathrm{mM}$ a $30^{\circ} \mathrm{C}$ depois de permanecerem durante $2 \mathrm{~h}$ em água destilada e serem lavados durante 30 minutos com $\mathrm{CaCl}_{2}$ 0,50 mM. Concluído o tempo de absorção, os cortes eram lavados com uma solução de $\mathrm{CaCl}_{2} \quad 0,50 \mathrm{mM}$ a $8^{\circ} \mathrm{C}$ durante 30 minutos.

Após a determinação química do boro absorvido, foi feita a análise cinética através dos parâmetros $\mathrm{Km}$ e $\mathrm{Vm}$, calculados pelos métodos de Hofstee e Lineweaver-Burk.

Os resultados mostraram a existência de pelo menos três mecanismos de absorção e evidenciaram, que a temperatura afeta os valores de $\mathrm{Km}_{1}$ e $V m_{1}$, mas não afeta os valores de $\mathrm{Km}_{2}$ e $\mathrm{Vm}_{2}$ referentes ao segundo mecanismo.

SARRUGE (1968), estudando o efeito das relações cálcio/boro e potássio/boro no desenvolvimento e sintomatologia do cafeeiro, cultivado em solução nutritiva, verificou que os teores de cálcio nas soluções influiram nas concentrações de fósforo, cálcio e magnésio no vegetal. Observou ainda, que o potássio afetou os teores de nitrogênio, potássio, cálcio, magnésio e boro do cafeeiro.

\section{MATERIAIS E METODOS}

0 trabalho foi constituído por uma série de ensaios de absorção, que consistiam em submeter cortes transversais de folhas de cafeeiros, 
cultivados em condições de campo, a concentrações crescentes de cálcio e a outras condições, características de cada ensaio.

Os ensaios realizados nas diferentes condições, foram comparados com outros, considerados como padrões.

As comparações foram feitas por métodos estatísticos e através dos parâmetros cinéticos $\mathrm{Km}$ e Vm, calculados para cada ensaio.

\section{Amostragem das folhas}

Para a realização de cada ensaio, foram colhidas 15 folhas de um bloco de cafeeiros da variedade Mundo Novo, com 3 anos de idade, constituído de 15 plantas, situado no campo experimental do Departamento de Solos e Geologia da Escola Superior de Agricultura «Luiz de Queiroz», Piracicaba - SP.

As folhas foram escolhidas entre as mais desenvolvidas do $3 .^{\circ}$ ou $4 .^{\circ}$ par, a contar do ápice dos ramos plagiótropos.

A seguir, as folhas foram lavadas, primeiramente com água corrente e em seguida com água desmineralizada.

\section{Obtenção dos cortes}

Depois de lavadas as folhas, foram cortadas placas de $2 \times 3 \mathrm{~cm}$ na porção média do limbo foliar, a fim de obter-se a quantidade de material necessária para a condução de um experimento.

As placas foram dispostas exatamente uma sobre a outra e colocadas entre duas placas mais grossas de batata (Solanum tuberosum, L.) formando um "sanduiche" retangular.

A seguir, colocava-se o «sanduíche» longitudinalmente no micrótomo tipo Reichert, calibrado para a obtenção de cortes com $300 \mu$ de espessura, e acionava-se a navalha o número necessário de vezes para a obtenção da quantidade de material seco a $70^{\circ} \mathrm{C}$, suficiente para a determinação do cálcio nas diferentes condições experimentais.

\section{Preparo das soluções de trabalho}

As soluções de trabalho foram preparadas por diluições sucessivas de uma solução de $\mathrm{CaCl}_{2} 2,56 \times 10^{-1} \mathrm{M}$, obtida a partir de $\mathrm{CaCO}_{3}$ e $\mathrm{HCl}$, correspondente a maior concentração da série de soluções estoque.

Depois de pesado, o $\mathrm{CaCO}_{3}$ foi transferido para copos de $2.000 \mathrm{ml}$, por meio de um volume de água suficiente para cobrir o soluto.

A seguir, adicionava-se $\mathrm{HCl}$ concentrado vagarosamente, para evitar projeções e agitava-se continuamente. Quando a solução ficava límpida, interrompia-se a adição de $\mathrm{HCl}$, deixava-se em repouso uma noite e com- 
pletava-se o volume. A solução assim obtida, tinha um $\mathrm{pH}$ de 5,49 , medido potenciometricamente.

Feitas as diluições, obteve-se uma série de soluções estoque com as seguintes concentrações de $\mathrm{Ca}$ :

$5 \times 10^{-4} \mathrm{M}, 10^{-3} \mathrm{M}, 2 \times 10^{-3} \mathrm{M}, 4 \times 10^{-3} \mathrm{M}, 8 \times 10^{-3} \mathrm{M}, 1,6 \times 10^{-2} \mathrm{M}, 3,2 \times$ $\times 10^{-2} \mathrm{M}, 6,4 \times 10^{-2} \mathrm{M}, 1,28 \times 10^{-1} \mathrm{M}, 2,5 \times 10^{-1} \mathrm{M}$.

Em cada uma destas soluções. foi adicionada, antes de completar o volume, uma solução contendo ${ }^{45} \mathrm{Ca}$ livre de carregador. $\mathrm{O}$ volume da solução radioativa foi determinado experimentalmente a fim de obter-se a atividade necessária para um número de contagens conveniente em cada solução de trabalho.

A série de soluções assim preparadas, foi transferida para frascos de polietileno de $1.000 \mathrm{ml}$, tapados por meio de uma rolha de borracha atravessada por uma pipeta de $5 \mathrm{ml}$.

As alíquotas foram retiradas, comprimindo-se o frasco para fazer subir a solução na pipeta. A seguir, removia-se a pipeta e transferia-se o contúdo para erlenmeyers de $700 \mathrm{ml}$, contendo os cortes de $495 \mathrm{ml}$ de água desmineralizada, a fim de obter-se a concentração correspondente a cada solução de trabalho.

\section{Técnica experimental}

Depois de feitos os cortes, os mesmos foram imediatamente recebidos em erlenmeyer de $700 \mathrm{ml}$, contendo cerca de $300 \mathrm{ml}$ de água desmineralizada na temperatura ambiente e com arejamento contínuo. A seguir, retirava-se a água e lavava-se os cortes com porções sucessivas de água desmineralizada.

Estas operações, eram feitas aspirando-se a água por meio de um tubo plástico ligado a uma trompa de vácuo, cuja extremidade era tampada por uma tela fina a fim de evitar que os cortes fossem aspirados.

Prosseguindo, colocavam-se $495 \mathrm{ml}$ de água desmineralizada nos erlenmeyers e transferiam-se para um banho de temperatura controlada, calibrado para a temperatura do experimento, e com luminosidade constante de 3.000 lux, obtida por meio de lâmpadas fluorescentes.

Nestas condições, os cortes permaneciam durante 60 minutos, a fim de se adaptarem às condições experimentais, antes da aplicação dos tratamentos.

Os tratamentos correspondentes ao ensaio padrão eram constituídos da seguinte série de concentrações de cálcio, contendo 0,1 a $4,0 \mu \mathrm{Ci} / 500 \mathrm{ml}$, obtida pela adição de uma alíquota de $5 \mathrm{ml}$ retirada de cada uma das soluções estoque: 
$5 \times 10^{-6} \mathrm{M}, 10^{-5} \mathrm{M}, 2 \times 10^{-5} \mathrm{M}, 4 \times 10^{-5} \mathrm{M}, 8 \times 10^{-5} \mathrm{M}, 1,6 \times 10^{-4} \mathrm{M}$, $3,2 \times 10^{-4} \mathrm{M}, 6,4 \times 10^{-4} \mathrm{M}, 1,28 \times 10^{-3} \mathrm{M}$ e $2,56 \times 10^{-3} \mathrm{M}$.

Em todos ensaios, os cortes foram mantidos nestas concentrações durante um período de 60 minutos o qual verificou-se experimentalmente, ser suficiente para manter a linearidade do fenômeno.

Decorrido este período, retiravam-se as soluções e mantinham-se os cortes durante 30 minutos em contato com uma solução de $\mathrm{CaCl}_{2} 2,56 \times$ $\times 10^{-3} \mathrm{M}$ a $10^{\circ} \mathrm{C}$, após sucessivas lavagens com a mesma.

Feita a dessorção, segundo a técnica explicada acima, com a finalidade de remover todo o cálcio do «ELA» (Espaço livre aparente), transferiam-se os cortes para um coador de plástico e lavavam-se os mesmos durante 30 segundos com água corrente.

Os cortes nestas condições, eram colocados na estufa a $70^{\circ} \mathrm{C}$, até peso constante, e transferidos para cadinhos de porcelana a fim de serem calcinados a $600^{\circ} \mathrm{C}$ até cinza clara.

\section{Determinação do cálcio absorvido}

Depois de calcinados os cortes, foi adicionado à cinza obtida, $1 \mathrm{ml}$ de $\mathrm{HCl} 0,01 \mathrm{~N}$ e retirada uma alíquota de $0,8 \mathrm{ml}$ para uma cubeta, na qual foram adicionadas duas a três gotas de $\mathrm{H}_{2} \mathrm{SO}_{4} \quad 0,01 \mathrm{~N}$ e de detergente.

A seguir, foi feita a secagem do material das cubetas em luz infravermelha e posteriormente a determinação da radioatividade por meio de um sistema de dectação e contagem Geiger-Müller.

Todas as contagens das amostras experimentais foram feitas paralelamente às dos padrões, obtidos com alíquotas das soluções estoques.

Feitas as contagens, calculou-se a velocidade do cálcio absorvido em íons microgramas de cálcio por grama de tecido e por hora.

\section{Determinação dos parâmetros de $\mathrm{Km}$ e $\mathrm{Vm}$}

0 método empregado para a determinação dos valores de $\mathrm{Km}$ e $\mathrm{Vm}$ foi o de Lineweaver--Burk, que se baseia no fato de que, os inversos dos membros da equação da hiperbole de Michaelis-Menten, aplicada a absorção iônica, é uma linha reta dada pela seguinte equação: (EPSTEIN \& HAGEN, 1952).

$$
\frac{1}{\mathrm{~V}}=\frac{1}{\mathrm{Vm}}+\frac{\mathrm{Km}}{\mathrm{Vm}} \times \frac{1}{\mathrm{~S}}
$$

equivalente à equação da linha reta 
Portanto, se o inverso da velocidade de absorção $1 / \mathrm{V}$ é traçado contra o inverso da concentração do substrato $1 / \mathrm{S}$, obtém-se uma linha reta cuja inclinação é $\mathrm{Km} / \mathrm{Vm}$ e cujo intercepto na ordenada $1 / \mathrm{V}$ é igual a $1 / \mathrm{Vm}$.

Assim sendo, determinou-se a equação da regressão linear para cada ensaio, a partir dos inversos das velocidades de absorção de cálcio e das concentrações das soluções de trabalho a fim de obter-se os valores de $\mathrm{Km}$ e Vm.

\section{Análise estatística}

A análise da variância e da regressão linear, para cada ensaio foi feita de acordo com PIMENTEL GOMES (1963), a partir dos valores inversos dos resultados obtidos.

Os ensaios realizados nas diferentes condições experimentais, foram comparados com os ensaios padrões por meio dos parâmetros $\mathrm{Km}$ e Vm calculados a partir dos valores «a» e «b», obtidos nas equações de regressão.

As comparações entre os valores de «a» ou entre os valores de b» foram feitas através do teste «t», considerando-se como limitante de significância o nível de $20 \%$ de probabilidade.

Quando o valor "t" alcançou o nível de significância, calculou-se os valores de $\mathrm{Km}$ e $\mathrm{Vm}$ correspondentes a cada valor de «a» e de «b».

Por outro lado, quando os valores de «t» não atingiram o nível de significância foi calculado um valor médio (ā) ponderado em relação às variâncias correspondentes a cada valor de «a».

\section{Ensaios realizados}

Absorção de cálcio na temperatura de $30^{\circ} \mathrm{C}$

Dois ensaios considerados como padrões, foram realizados de acordo com as técnicas experimentais aplicadas anteriormente, calibrando-se o banho de temperatura controlada a $30^{\circ} \mathrm{C}$.

Os ensaios foram constituídos de quatro repetições e foram realizados na fase vegetativa e na fase de frutificação dos cafeeiros, a fim de servir de comparação para os demais.

Absorção de cálcio à temperatura de $10^{\circ} \mathrm{C}$

Este experimento foi conduzido mantendo-se os cortes, desde a fase de adaptação às condições experimentais, na temperatura de $10^{\circ} \mathrm{C}$, calibrando-se o banho para esta temperatura e adaptando-se às faces do mesmo, placas de isopor a fim de diminuir as trocas de calor com o ambiente. As demais condições foram as mesmas dos ensaios padrões.

Absorção de cálcio em função do nitrogênio como inibidor do processo respiratório 
Este ensaio foi conduzido nas mesmas condições dos ensaios padrões, substituindo-se o arejamento pelo borbulhamento contínuo com nitrogênio.

Absorção de cálcio em função do 2,4-Dinitrofenol como inibidor do processo respiratório

Este experimento foi realizado nas mesmas condições do ensaio padrão e na presença de 2,4 DNP $10^{-5} \mathrm{M}$.

0 inibidor foi adicionado durante a fase de adaptação dos cortes às condições experimentais.

Absorção de cálcio em presença de potássio

Este ensaio foi conduzido adicionando-se $\mathrm{KCl}{ }^{10-4} \mathrm{M}$, simultaneamente à adição de cálcio e mantendo-se as mesmas condições dos experimentos padrões.

Como os resultados obtidos acusaram um efeito sinergético, que poderia ser devido à concentração de potássio empregada, o ensaio foi repetido com KCL $5 \times 10^{-3} \mathrm{M}$.

Absorção de cálcio em presença do magnésio

Este experimento foi realizado nas mesmas condições dos ensaios padrões, adicionando-se $\mathrm{MgCl}_{2} .6 \mathrm{H}_{2} \mathrm{O} 5 \times 10^{-3} \mathrm{M}$ simultaneamente à adição de cálcio, mantendo-se as mesmas condições dos ensaios padrões.

Absorção de cálcio em presença do boro

Este ensaio foi conduzido, adicionando-se $\mathrm{H}_{3} \mathrm{BO}_{3} 5 \times 10^{-3} \mathrm{M}$ simultaneamente à adição de cálcio, mantendo-se as mesmas condições dos ensaios padrões. 


\section{RESULTADOS}

Absorção de cálcio na fase vegetativa dos cafeeiros

0 Quadro I mostra os valores dos inversos da velocidade de cálcio absorvido e da concentração de cálcio na solução externa, correspondentes ao ensaio padrão conduzido na fase vegetativa dos cafeeiros.

QUADRO I - Valores dos inversos da concentração molar de cálcio (1/lCal) na solução externa e da velocidade de cálcio absorvido (1/V), em ions $\mu \mathrm{g} / \mathrm{g} / \mathrm{h}$ nas quatro repetições.

\begin{tabular}{cllll}
\hline (1/ICaI) & \multicolumn{5}{c}{$1 / \mathrm{V}$} \\
\hline $1 / 5,00 \times 10-6$ & 0,517 & 0,258 & 0,472 & 0,363 \\
$1 / 1,00 \times 10-5$ & 0,259 & 0,206 & 0,161 & 0,292 \\
$1 / 2,00 \times 10-5$ & 0,107 & 0,069 & 0,077 & 0,098 \\
$1 / 4,00 \times 10-5$ & 0,065 & 0,095 & 0,086 & 0,109 \\
$1 / 8,00 \times 10-5$ & 0,070 & 0,040 & 0,056 & 0,078 \\
$1 / 1,60 \times 10-4$ & 0,063 & 0,057 & 0,068 & 0,080 \\
$1 / 3,20 \times 10-4$ & 0,047 & 0,070 & 0,042 & 0,067 \\
$1 / 6,40 \times 10-4$ & 0,049 & 0,063 & 0,042 & 0,077 \\
$1 / 1,28 \times 10-3$ & 0,057 & 0,034 & 0,039 & 0,040 \\
$1 / 2,56 \times 10-3$ & 0,041 & 0,039 & 0,041 & 0,031 \\
\hline
\end{tabular}

Resultados da análise da regressão e valores de $\mathrm{Km}$ e $\mathrm{Vm}$

Regressão Linear (F)

Desvio da Regressão (F)

Coeficiente de Variação (CV\%)

Equação de Regressão

$\mathrm{Km}$

$\mathrm{Vm}$

(***) - significativo ao nível de $1 \%$ de probabilidade

(ns) - não significativo
$256,440 * * *$

0,667 ns

$37,9 \%$

$1 / \mathrm{V}=42,129 \times 10-3+1,780 \times 10-61 / \mathrm{Ca}$

$42,250 \times 10-6 \mathrm{M}$ 23,740 ions $\mathrm{ug} / \mathrm{g} / \mathrm{h}$ 
Absorção de cálcio em função do nitrogênio como inibidor do processo respiratório

O Quadro III mostra os valores dos inversos da velocidade do cálcio absorvido e da concentração de cálcio na solução externa, correspondentes ao ensaio em que o borbulhamento de ar foi substituído pelo borbulhamento com nitrogênio.

Quadro II - Valores dos inversos da concentração molar de cálcio (1/ICaI) na solução externa e da velocidade de cálcio absorvido $(1 / \mathrm{V})$ em ions $\mu \mathrm{g} / \mathrm{g} / \mathrm{h}$ nas quatro repetições.

\begin{tabular}{ccccr}
\hline (1/ICaI) & \multicolumn{3}{c}{$1 / \mathrm{V}$} \\
\hline $1 / 5,00 \times 10-6$ & 0,631 & 0,347 & 0,779 & 0,470 \\
$1 / 1,00 \times 10-5$ & 0,255 & 0,155 & 0,307 & 0,220 \\
$1 / 2,00 \times 10-5$ & 0,229 & 0,130 & 0,175 & 0,257 \\
$1 / 4,00 \times 10-5$ & 0,082 & 0,057 & 0,119 & 0,116 \\
$1 / 8,00 \times 10-5$ & 0,075 & 0,079 & 0,109 & 0,126 \\
$1 / 1,60 \times 10-4$ & 0,044 & 0,049 & 0,063 & 0,072 \\
$1 / 3,20 \times 10-4$ & 0,062 & 0,050 & 0,071 & 0,073 \\
$1 / 6,40 \times 10-4$ & 0,059 & 0,067 & 0,072 & 0,074 \\
$1 / 1,28 \times 10-3$ & 0,077 & 0,042 & 0,068 & 0,093 \\
$1 / 2,56 \times 10-3$ & 0,051 & 0,042 & 0,069 & 0,079 \\
\hline
\end{tabular}

Resultados da análise da regressão e valores de $\mathrm{Km}$ e $\mathrm{Vm}$

Regressão Linear (F)

Desvio da Regressão (F)

Coeficiente de Variação (CV\%)

$44,95 \%$

Equação de Regressão

$1 / \mathrm{V}=54,849 \times 10-3+2,420 \times 10-61 / \mathrm{Ca}$

$\mathrm{Km}$

$44,154 \times 10-6$

$\mathrm{Vm}$

(***) - significativo ao nivel de $1 \%$ de probabilidade

(ns) - não significativo 
Absorção de cálcio na fase de frutificação dos cafeeiros

0 Quadro II mostra os valores dos inversos da velocidade de cálcio absorvido e de concentração de cálcio na solução externa, correspondentes ao ensaio padrão conduzido na fase de frutificação dos cafeeiros.

Quadro III - Valores dos inversos da concentração molar de cálcio (1/ICaI) na solução externa e da velocidade de cálcio absorvido (1/V) em íns $\mu \mathrm{g} / \mathrm{g} / \mathrm{h}$ nas quatro repetições.

\begin{tabular}{ccccr}
\hline \multicolumn{1}{c}{$1 /$ ICaI } & \multicolumn{5}{c}{ } \\
\hline $1 / 5,00 \times 10-6$ & 0,333 & 0,445 & 0,845 & 0,736 \\
$1 / 1,00 \times 10-5$ & 0,224 & 0,227 & 0,264 & 0,368 \\
$1 / 2,00 \times 10-5$ & 0,128 & 0,196 & 0,178 & 0,176 \\
$1 / 4,00 \times 10-5$ & 0,066 & 0,100 & 0,061 & 0,167 \\
$1 / 8,00 \times 10-5$ & 0,051 & 0,100 & 0,051 & 0,067 \\
$1 / 1,60 \times 10-4$ & 0,054 & 0,045 & 0,052 & 0,075 \\
$1 / 3,20 \times 10-4$ & 0,050 & 0,055 & 0,053 & 0,055 \\
$1 / 6,40 \times 10-4$ & 0,063 & 0,033 & 0,035 & 0,071 \\
$1 / 1,28 \times 10-3$ & 0,039 & 0,052 & 0,037 & 0,071 \\
$1 / 2,56 \times 10-3$ & 0,038 & 0,052 & 0,034 & 0,041 \\
\hline
\end{tabular}

Resultados da análise da regressão de valores de $\mathrm{Km}$ e $\mathrm{Vm}$

Regressão Linear (F)

Desvio de Regressão (F)

Coeficiente de Variação (CV\%)

Equação de Regressão

$\mathrm{Km}$

$\mathrm{Vm}$

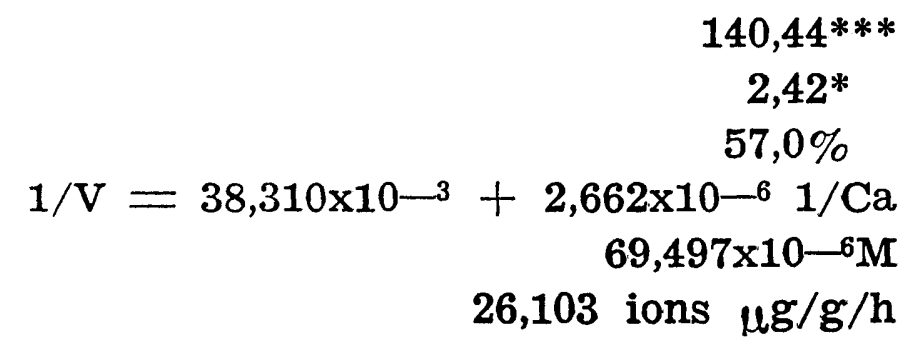

$140,44 * * *$

$2,42 *$

$57,0 \%$

$1 / \mathrm{V}=38,310 \times 10-3+2,662 \times 10-61 / \mathrm{Ca}$

$69,497 \times 10-6 \mathrm{M}$

26,103 ions $\mu g / g / h$

(***) - significativo ao nível de $1 \%$ de probabilidade

(*) - significativo ao nivel de $5 \%$ de probabilidade 
Absorção de cálcio em função do 2,4 Dinitrofenol como o inibidor do processo respiratório

O Quadro IV mostra os valores dos inversos da velocidade de cálcio absorvido e da concentração de cálcio na solução externa, na presença de 2,4 Dinitrofenol $10^{-5} \mathrm{M}$.

Quadro IV - Valores dos inversos da concentração molar de cálcio (1/ICaI) na solução externa e da velocidade de cálcio absorvido (1/V) em fons $\mu \mathrm{g} / \mathrm{g} / \mathrm{h}$ nas quatro repetições.

\begin{tabular}{ccccr}
\hline \multicolumn{1}{c}{$1 / \mathrm{ICaI}$} & \multicolumn{5}{l}{$\mathrm{V}$} \\
\hline $1 / 5,00 \times 10-6$ & 0,587 & 0,727 & 0,550 & 0,627 \\
$1 / 1,00 \times 10-5$ & 0,286 & 0,280 & 0,329 & 0,369 \\
$1 / 2,00 \times 10-5$ & 0,114 & 0,161 & 0,149 & 0,193 \\
$1 / 4,00 \times 10-5$ & 0,141 & 0,127 & 0,089 & 0,107 \\
$1 / 8,00 \times 10-5$ & 0,112 & 0,127 & 0,106 & 0,101 \\
$1 / 1,60 \times 10-4$ & 0,097 & 0,111 & 0,088 & 0,073 \\
$1 / 3,20 \times 10-4$ & 0,094 & 0,081 & 0,086 & 0,057 \\
$1 / 6,40 \times 10-4$ & 0,080 & 0,087 & 0,058 & 0,079 \\
$1 / 1,28 \times 10-3$ & 0,084 & 0,093 & 0,081 & 0,050 \\
$1 / 2,56 \times 10-3$ & 0,078 & 0,095 & 0,072 & 0,053
\end{tabular}

Resultados da análise da regressão e valores de $\mathrm{Km}$ e $\mathrm{Vm}$

Regressão Linear (F)

Desvio da Regressão (F)

Coeficiente de variação (CV\%)

Equação de Regressão

$\mathrm{Km}$

$\mathrm{Vm}$

$1022,36^{* * *}$
$1,68 \mathrm{~ns}$
$18,90 \%$
$1 / \mathrm{V}=64,560 \times 10-3+2,688 \times 10-61 / \mathrm{Ca}$
$41,634 \times 10-6 \mathrm{M}$
15,489 ions $\mu \mathrm{g} / \mathrm{g} / \mathrm{h}$

(***) - significativo ao nivel de $1 \%$ de probabilidade

(ns) - não significativo 
Absorção de cálcio em presença de potássio ( $\mathrm{KCl} 10^{-4} \mathrm{M}$ )

O Quadro VI mostra os valores dos inversos da velocidade de cálcio absorvido e da concentração de cálcio na solução externa, na presença de $\mathrm{KCl} 10^{-4} \mathrm{M}$.

Quadro VI - Valores dos inversos da concentração molar de cálcio (1/ICaI) na solução externa e da velocidade de cálcio absorvido (1/V) em ions $\mu \mathrm{g} / \mathrm{g} / \mathrm{h}$ nas quatro repetições.

\begin{tabular}{lllll}
\hline \multicolumn{1}{c}{$1 / \mathrm{ICaI}$} & \multicolumn{5}{l}{$1 / \mathrm{V}$} \\
\hline $1 / 5,00 \times 10-6$ & 0,459 & 0,380 & 0,443 & 0,312 \\
$1 / 1,00 \times 10-5$ & 0,187 & 0,305 & 0,191 & 0,177 \\
$1 / 2,00 \times 10-5$ & 0,101 & 0,170 & 0,162 & 0,122 \\
$1 / 4,00 \times 10-5$ & 0,075 & 0,104 & 0,081 & 0,061 \\
$1 / 8,00 \times 10-5$ & 0,074 & 0,083 & 0,067 & 0,086 \\
$1 / 1,60 \times 10-4$ & 0,062 & 0,076 & 0,056 & 0,076 \\
$1 / 3,20 \times 10-4$ & 0,062 & 0,077 & 0,056 & 0,062 \\
$1 / 6,40 \times 10-4$ & 0,052 & 0,083 & 0,053 & 0,069 \\
$1 / 1,28 \times 10-3$ & 0,059 & 0,065 & 0,058 & 0,060 \\
$1 / 2,56 \times 10-3$ & 0,030 & 0,059 & 0,038 & 0,048 \\
\hline
\end{tabular}

Resultados da análise da regressão e valores de $\mathrm{Km}$ e $\mathrm{Vm}$

Regressão Linear (F)

Desvio da regressão (F)

Coeficiente de variação (CV\%)

Equação de Regressão

$\mathrm{Km}$

$\mathrm{Vm}$
$425,37 * * *$

$0,29 \mathrm{~ns}$

$26,34 \%$

$1 / \mathrm{V}=53,098 \times 10-3+1,700 \times 10-61 / \mathrm{Ca}$

$32,013 \times 10-6$

18,333 ions $\mu \mathrm{g} / \mathrm{g} / \mathrm{h}$

$(* * *)$ - significativo ao nível de $1 \%$ de probabilidade

(ns) - não significativo 
Absorção de cálcio em presença de potássio ( $\mathrm{KCl} 5 \times 10^{-3} \mathrm{M}$ )

O Quadro VII mostra os valores dos inversos da velocidade de cálcio absorvido e da concentração de cálcio na solução externa, na presença de $\mathrm{KCl} 5 \times 10^{-3} \mathrm{M}$.

Quadro VII - Valores dos inversos da concentração molar de cálcio (1/ICaI) na solução externa e da velocidade de cálcio absorvido (1/V) em ions $\mu \mathrm{g} / \mathrm{g} / \mathrm{h}$ nas quatro repetições.

\begin{tabular}{ccccr}
\hline $1 /$ ICaI & \multicolumn{5}{l}{$1 / \mathrm{V}$} \\
\hline $1 / 5,00 \times 10-6$ & 0,487 & 0,491 & 0,622 & 0,448 \\
$1 / 1,00 \times 10-5$ & 0,272 & 0,231 & 0,207 & 0,214 \\
$1 / 2,00 \times 10-5$ & 0,112 & 0,131 & 0,127 & 0,125 \\
$1 / 4,00 \times 10-5$ & 0,095 & 0,128 & 0,076 & 0,080 \\
$1 / 8,00 \times 10-5$ & 0,057 & 0,097 & 0,077 & 0,074 \\
$1 / 1,60 \times 10-4$ & 0,085 & 0,109 & 0,082 & 0,059 \\
$1 / 3,20 \times 10-4$ & 0,068 & 0,099 & 0,085 & 0,046 \\
$1 / 6,40 \times 10-4$ & 0,057 & 0,063 & 0,083 & 0,050 \\
$1 / 1,28 \times 10-3$ & 0,047 & 0,079 & 0,070 & 0,051 \\
$1 / 2,56 \times 10-3$ & 0,049 & 0,064 & 0,072 & 0,050 \\
\hline
\end{tabular}

Resultados da análise da regressão e valores de $\mathrm{Km}$ e $\mathrm{Vm}$

Regressão Linear (F)

Desvio da Regressão (F)

$776,84 * * *$

Coeficiente de variação (CV\%)

$2,41^{*}$

Equação de Regressão

$21,74 \%$

$\mathrm{Km}$

$1 / \mathrm{V}=51,531 \times 10-3+2,163 \times 10-61 / \mathrm{Ca}$

$\mathrm{Vm}$

(***) - significativo ao nível de $1 \%$ de probabilidade

(*) - significativo ao nível de $5 \%$ de probabilidade 
Absorção de cálcio em presença de magnésio

O Quadro VIII mostra os valores dos inversos da velocidade de cálcio absorvido e da concentração do cálcio na solução externa, na presença de $\mathrm{MgCl}_{2} 5 \times 10^{-3} \mathrm{M}$.

Quadro VIII - Valores dos inversos da concentração molar de cálcio (1/ICaI) na solução externa e da velocidade de cálcio absorvido (1/V) em ions $\mu \mathrm{g} / \mathrm{g} / \mathrm{h}$ nas quatro repetições.

\begin{tabular}{lrrrr}
\hline \multicolumn{1}{c}{$1 / \mathrm{ICaI}$} & \multicolumn{5}{c}{$\mathrm{V}$} \\
\hline $1 / 5,00 \times 10-6$ & 11,494 & 9,804 & $\mathbf{7 , 3 5 3}$ & $\mathbf{1 0 , 8 7 0}$ \\
$1 / 1,00 \times 10-5$ & 10,000 & 6,757 & 4,762 & 13,699 \\
$1 / 2,00 \times 10-5$ & 5,405 & 4,926 & 1,988 & 5,495 \\
$1 / 4,00 \times 10-5$ & 2,571 & 2,096 & 1,795 & 2,326 \\
$1 / 8,00 \times 10-5$ & 1,572 & 1,302 & 0,979 & 1,429 \\
$1 / 1,60 \times 10-4$ & 0,949 & 0,908 & 0,779 & 0,962 \\
$1 / 3,20 \times 10-4$ & 0,752 & 0,689 & 0,442 & 0,605 \\
$1 / 6,40 \times 10-4$ & 0,453 & 0,369 & 0,294 & 0,439 \\
$1 / 1,28 \times 10-3$ & 0,379 & 0,368 & 0,233 & 0,242 \\
$1 / 2,56 \times 10-3$ & 0,230 & 0,157 & 0,160 & 0,186 \\
\hline
\end{tabular}

Resultados da análise da regressão e valores de $\mathrm{Km}$ e $\mathrm{Vm}$

Regressão Linear (F)

Desvio da Regressão (F)

Coeficiente de Variação (CV\%)

Equação de Regressão

$\mathrm{Km}$

$\mathrm{Vm}$

(*) - significativo ao nível de $5 \%$ de probabilidade
$197,792^{* * *}$

$2,720 *$

$50,59 \%$

$1 / \mathrm{V}=768,633 \times 10-3+5,347 \times 10-61 / \mathrm{Ca}$

$69,569 \times 10-6$ 1,301 ions $\mu g / g / h$ 
Absorção de cálcio em presença do boro

O Quadro IX mostra os valores dos inversos da velocidade de cálcio absorvido e da concentração de cálcio na solução externa, na presença de $\mathrm{H}_{3} \mathrm{BO}_{3} 5 \times 10^{-3} \mathrm{M}$.

Quadro IX - Valores dos inversos da concentração molar de cálcio (1/ICaI) na solução externa e da velocidade de cálcio absorvido (1/V) em íns $\mathrm{\mu g} / \mathrm{g} / \mathrm{h}$ nas quatro repetições.

\begin{tabular}{cllll}
\hline $1 /$ ICaI & \multicolumn{5}{c}{$1 / V$} \\
\hline $1 / 5,00 \times 10-6$ & 0,609 & 0,586 & 1,135 & 0,549 \\
$1 / 1,00 \times 10-5$ & 0,329 & 0,492 & 0,334 & 0,294 \\
$1 / 2,00 \times 10-5$ & 0,251 & 0,264 & 0,413 & 0,130 \\
$1 / 4,00 \times 10-5$ & 0,200 & 0,127 & 0,202 & 0,108 \\
$1 / 8,00 \times 10-5$ & 0,149 & 0,112 & 0,168 & 0,116 \\
$1 / 1,60 \times 10-4$ & 0,138 & 0,103 & 0,126 & 0,087 \\
$1 / 3,20 \times 10-4$ & 0,100 & 0,098 & 0,109 & 0,075 \\
$1 / 6,40 \times 10-4$ & 0,98 & 0,097 & 0,097 & 0,058 \\
$1 / 1,28 \times 10-3$ & 0,94 & 0,064 & 0,095 & 0,065 \\
$1 / 2,56 \times 10-3$ & 0,75 & 0,067 & 0,073 & 0,054 \\
\hline
\end{tabular}

Resultados da análise da regressão e valores de $\mathrm{Km}$ e $\mathrm{Vm}$

Regressão Linear (F)

Desvio da Regressão (F)

Coeficiente de variação (CV\%)

Equação de Regressão

$\mathrm{Km}$

$\mathrm{Vm}$

(***) - significativo ao nivel de $1 \%$ de probabilidade

(ns) - não significativo

$$
\begin{array}{r}
142,104^{* * *} \\
0,123 \mathrm{~ns} \\
48,70 \% \\
1 / \mathrm{V}=83,412 \times 10-3+3,131 \times 10-61 / \mathrm{Ca} \\
37,536 \times 10-6 \\
11,989 \text { ions } \mu g / \mathrm{g} / \mathrm{h}
\end{array}
$$


Comparação entre os valores de ka» e «b» das equações de regressão linear, relativos aos diversos ensaios

O Quadro X mostra os valores de «t», relativos à comparação entre os valores de «a» e «b», das equações de regressão linear, obtidos nos diversos ensaios e nos ensaios padrões.

QUADRO X - Valores de «t» relativos a comparação entre «a» e «b» dos vários ensaios com os valores de (ap e bp) dos ensaios padrões obtidos através da regressão linear.

\begin{tabular}{lcc}
\hline & \multicolumn{2}{c}{$t$} \\
\cline { 2 - 3 } EXPERIMENTOS & $\mathrm{a}-\mathrm{ap}$ & $\mathrm{b}-\mathrm{bp}$ \\
\hline $\mathrm{N}_{2}$ & 0,930 & $3,710^{*}$ \\
$\mathrm{DNP}$ & 0,685 & $1,731^{*}$ \\
$10^{\circ} \mathrm{C}$ & 0,300 & $4,54^{*}$ \\
$\mathrm{KCl} 10^{-4} \mathrm{M}$ & 0,124 & $3,730^{*}$ \\
$\mathrm{KCl} 5 \times 10^{-3} \mathrm{M}$ & 0,240 & $1,350^{*}$ \\
$\mathrm{Mg} \mathrm{Cl}_{2} 5 \times 10^{-3} \mathrm{M}$ & $2,568^{*}$ & $13,411^{*}$ \\
$\mathrm{H}_{3} \mathrm{BO}_{3} 5 \times 10^{-3} \mathrm{M}$ & $1,239^{*}$ & $2,246^{*}$ \\
\hline
\end{tabular}

$\left(^{*}\right)$ - significativos ao nível de $20 \%$ de probabilidade 
Parâmetros obtidos após a comparação estatística dos valores de «a» e «b» das equações de regressão linear

O Quadro XI mostra os valores dos parâmetros $\mathrm{Km}$ e Vm obtidos após a comparação estatística, pelo teste «t», e os valores de 《a» e «b» das equações de regressão linear, relativos aos diversos ensaios e aos ensaios padrões.

QUADRO XI - Valores dos parâmetros $\mathrm{Km}$ e Vm, e de a, b e ā, correspondentes aos diversos ensaios e aos ensaios padrões.

\begin{tabular}{|c|c|c|c|c|c|}
\hline EXPERIMENTOS & $a\left(x 10^{3}\right)$ & $\bar{a}\left(\mathrm{x} 10^{3}\right)$ & $\mathrm{b}\left(\mathrm{x} 10^{6}\right)$ & $\begin{array}{c}\mathrm{Vm} \\
\text { ions }) \mu \mathrm{g} / \\
/ \mathrm{g} / \mathrm{h})\end{array}$ & $\underset{\left(\times 10^{6}\right.}{\mathrm{Km}}$ \\
\hline Padrão & 42,129 & 36,614 & 1,780 & 27,312 & 46,562 \\
\hline $\mathrm{N}_{2}$ & 38,310 & , & 2,662 & 27,312 & 72,715 \\
\hline Padrão & 54,849 & 61,410 & 2,420 & 16,284 & 39,436 \\
\hline DNP & 64,560 & , & 2,688 & 16,284 & 43,771 \\
\hline Padrão & 54,849 & 52,061 & 2,42 & 19,208 & 46,515 \\
\hline $10^{\circ} \mathrm{C}$ & 47,538 & , & 3,937 & 19,208 & 75,627 \\
\hline Padrão & 54,849 & 53,659 & 2,420 & 18,636 & 45,132 \\
\hline $\mathrm{KCl} 10^{-4} \mathrm{M}$ & 53,098 & , & 2,420 & 18,636 & 31,678 \\
\hline Padrão & 54,849 & 52,404 & 2,420 & 19,083 & 46,214 \\
\hline $\mathrm{KCl} 5 \times 10^{-3} \mathrm{M}$ & 51,531 & , & 2,163 & 19,083 & 41,280 \\
\hline Padrão & 54,849 & , & 2,420 & 23,740 & 42,250 \\
\hline $\mathrm{MgCl}_{2} 5 \times 10^{-3} \mathrm{M}$ & 786,633 & , & 5,347 & 1,301 & 69,569 \\
\hline Padrão & 54,849 & , & 2,420 & 23,740 & 42,250 \\
\hline $\mathrm{H}_{3} \mathrm{BO}_{3} 5 \times 10^{-3} \mathrm{M}$ & 83,4012 & , & 3,131 & 11,989 & 37,536 \\
\hline
\end{tabular}

\section{DISCUSSÁO}

Absorção de cálcio em função de sua concentração na solução externa

Os resultados apresentados nos Quadros I a X, referentes aos diversos ensaios realizados, mostram que as relações entre os valores dos inversos das velocidades de cálcio absorvido e das concentrações de cálcio nas soluções externas, são descritas por uma linha reta, conforme pode ser observado na análise de regressão. Estas análises mostram o efeito significativo da regressão linear, em todos os ensaios realizados. 
A linearidade constatada, evidencia que a velocidade de cálcio absorvido é uma função quadrática da concentração externa e demonstra que a absorção de cálcio segue a equação de Michaelis-Menten (SMITH \& EPSTEIN, 1964).

Segundo MOORE (1972), quando a velocidade de absorção aumenta com a concentração externa, até um limite em que o sistema fica saturado, isto é, atinge uma velocidade máxima, pode-se concluir que trata-se, provavelmente, de um processo ativo uma vez que o processo passivo não se comporta desta forma.

A análise de regressão mostra ainda, os baixos níveis de significiência dos desvios de regressão, nos ensaios em que estes desvios foram significativos, evidenciando que o cálcio, na faixa de concentração de $5 \times 10^{-6}$ a $2,56 \times 10^{-3} \mathrm{M}$, é absorvido através de um mecanismo único.

Este fato não está de acordo com EPSTEIN (1966), o qual cita que a absorção de íons é governada por dois mecanismos diferentes. 0 primeiro mecanismo opera nas concentrações de 0,002 a $0,2 \mathrm{mM}$ e o segundo de 0,50 a $50 \mathrm{mM}$. As mais recentes evidências de estudos feitos com vários tecidos indicam que o mecanismo duplo é um aspecto da fisiologia celular independente das características anatômicas e histológicas.

Por outro lado, SMITH \& ROBINSON (1971) trabalhando com cortes de folhas de laranjeiras, colhidas no campo, verificaram a existência de um mecanismo único de absorção para o sódio e potássio.

A não observância do mecanismo duplo parece estar vinculada à baixa precisão dos ensaios desta natureza, quando conduzidos com amostras de campo, conforme podemos observar pelos altos valores dos coeficientes da variação obtidos.

Os valores de $\mathrm{Km}$ e $\mathrm{Vm}$, referentes aos ensaios padrões, apresentados nos Quadros I e II, indicam que as amostras colhidas em fases distintas do ciclo do cafeeiro podem conduzir a valores cinéticos diferentes. Efeitos dos linibidores do processo respiratório e da temperatura de $10^{\circ} \mathrm{C}$

No Quadro XI pode-se observar os valores de $\mathrm{Km}$ correspondentes aos ensaios com aplicação de $\mathrm{N}^{2}$ e DNP, os quais são significativamente diferentes e maiores que os valores de $\mathrm{Km}$ dos ensaios padrões.

Este fato mostra que a falta de oxigênio e a presença do DNP como desacoplador da fosforilação oxidativa (RAINZ, 1968), inibem a absorção de cálcio pelos tecidos foliares.

Segundo MOORE (1972) "a falta do oxigênio inibe a fosforificação oxidativa e o transporte eletrônico sugerindo um envolvimento desses processos com o transporte iônico. Outrossim, a inibição do transporte pela inibição do processo respiratório é um forte suporte de uma conexão direta entre metabolismo e transporte».

Embora as observações de Moore, conduzam à afirmação de que a absorção do cálcio nas condições estudadas, é metabólica, ROBINSONN \& 
SMITH (1970) citam que a inibição da absorção de $\mathrm{Cl}-$ por DNP sugere a relação entre a fosforilação oxidativa e a absorção, entretanto a inibição pode ser devida a um efeito direto na membrana.

BLINKS et al. (1938) citado por WAISEL (1962) mostraram que os efeitos do DNP e $\mathrm{N}_{2}$, não estão confinados somente ao processo metabólico de absorção, mas também ao decréscimo da permeabilidade da membrana.

No Quadro XI observa-se que os valores de Vm, relativos aos ensaios com $\mathrm{N}_{2}$, DNP e aos padrões correspondentes são iguais, indicando que, em ambas condições, o $\mathrm{Ca}$ atinge o mesmo ponto máximo de absorção.

Este fato evidencia que a inibição observada na absorção do cálcio, não foi devida ao decréscimo da permeabilidade da membrana celular mas somente à alteração do processo metabólico.

A inibição metabólica por $\mathrm{N}_{2}$ e DNP na absorção iônica de diversos íons foi constatada por vários autores (BOWEN, 1969; JACOBY \& PLESSNER, 1970; RAINZ, 1968).

Segundo MOORE (1972), como todos os inibidores afetam a produção ou utilização de ATP, parece claro o seu envolvimento no processo de transporte. Há uma quase perfeita correlação entre o transporte iônico e a atividade de ATPase conforme (FISHER \& HODGES, 1969, FISHER, HANSEN \& HODGES, 1970).

Como o consumo de energia, segundo EPSTEIN \& LEGGETT (1954) constitui uma das características do transporte ativo. Os resultados obtidos sobre os efeitos de $\mathrm{N}_{2}$ e DNP, constituem mais uma evidência da absorção metabólica do cálcio por tecidos foliares.

As observações feitas com relação aos efeitos de $\mathrm{N}_{2}$ e DNP são corroboradas pelos resultados obtidos com os ensaios de absorção de cálcio na temperatura de $10^{\circ} \mathrm{C}$.

No Quadro XI observa-se que o valor do $\mathrm{Km}$, dos ensaios conduzidos na temperatura de $10^{\circ} \mathrm{C}$, é maior que o dos ensaios padrões correspondentes, enquanto que os valores de $\mathrm{Vm}$ são iguais.

Estes resultados mostram que, a absorção do cálcio é inibida na temperatura de $10^{\circ} \mathrm{C}$, pois o maior valor de $\mathrm{Km}$ indica uma diminuição da afinidade do íon com o carregador.

Segundo RAINZ (1969) e SCHIMID, HAAG \& EPSTEIN (1965) o processo de transporte iônico é altamente dependente da temperatura e essencialmente alterado por temperaturas próximas de $0^{\circ} \mathrm{C}$. Este fato, segundo MOORE (1972), não é suficiente para provar o vínculo direto do metabolismo com o transporte, uma vez que, todo o processo pode ser alterado e a permeabilidade da membrana ser grandemente reduzida.

Entretanto, a igualdade dos valores de Vm, conforme observou-se para o efeito dos inibidores, indica que a inibição não é devida à dimi- 
nuição da permeabilidade da membrana, e sim a uma alternação do processo metabólico.

\section{Efeitos do potássio, magnésio e boro na absorção de cálcio}

O valor de $\mathrm{Km}$ referente a absorção de cálcio em presença de $\mathrm{KCl}$ $10^{-4} \mathrm{M}$, apresentado no Quadro XI mostra que o potássio estimulou a absorção do cálcio, uma vez que o mesmo, é significativamente menor que o $\mathrm{Km}$ do ensaio padrão.

Este estímulo da absorção do cálcio, parece estar vinculado, a um aumento da afinidade do cálcio, pelos pontos de ligação da substância que funciona como carregador para ambos os íons, em virtude dos valores iguais de $\mathrm{Vm}$.

Os valores de $\mathrm{Km}$ e $\mathrm{Vm}$ relativos aos efeitos de $\mathrm{KCl} 5 \times 10^{-3} \mathrm{M}$ evidenciam que, as observações feitas anteriormente não foram devidas a concentrações excessivamente baixas de potássio.

Entretanto, segundo MAAS (1969), o efeito depressivo do potássio na absorção do cálculo é claramente observado na faixa de $1-10 \mathrm{emg} / 1 \mathrm{de} \mathrm{K}$. $0 \mathrm{Li}^{+}$e o $\mathrm{K}^{+}$reduzem grandemente a absorção de cálcio pois os efeitos são constatados em uma concentração 100 vezes maior de $\mathrm{Ca}$. Os resultados obtidos sugerem um efeito competitivo do potássio na absorção do cálcio.

O efeito do magnésio na absorção do cálcio, pode ser observado através dos valores de $\mathrm{Km}$ e $\mathrm{Vm}$, apresentados no Quadro XI. Verifica-se neste quadro, que o valor de $\mathrm{Km}$ correspondente a $\mathrm{Mg} \mathrm{Cl}_{2} 5 \times 10^{-3} \mathrm{M}$ é maior que o valor de $\mathrm{Km}$ do ensaio padrão. Este aspecto demonstra que o magnésio é um inibidor da absorção do cálcio. Por outro lado, considerando os valores diferentes de Vm, conclui-se que o efeito inibidor é não competitivo, indicando que o magnésio está vinculado a outros pontos de ligação dos carregadores, diferentes do cálcio.

EPSTEIN \& LEGGETT (1954) verificaram que os íons $\mathrm{Ca}, \mathrm{Sr}$ e $\mathrm{Ba}$ competem pelos mesmos pontos de ligação nos carregadores enquanto que o íon $\mathrm{Mg}$ não compete por estes pontos. Resultados semelhantes foram obtidos por COLLANDER (1941) que cultivou plantas de dez gêneros diferentes, em soluções contendo $\mathrm{Mg}$, $\mathrm{Ca}$ e $\mathrm{Sr}$, e verificou um acentuado paralelismo entre a absorção de $\mathrm{Ca}$ e $\mathrm{Sr}$; por outro lado, a absorção de $\mathrm{Mg}$ não foi consistente com a absorção dos outros dois íons. 0 autor deste estudo conclui que $\mathrm{Ca}$ e $\mathrm{Sr}$, estão ligados aos mesmos pontos e competem um com outro, enquanto que $\mathrm{Mg}$ está ligado a outros pontos.

Os efeitos do boro na absorção de cálcio podem ser observados no Quadro XI. Os valores de $\mathrm{Km}$ e Vm, correspondentes aos ensaios padrões e aos ensaios com $\mathrm{H}_{3} \mathrm{BO}_{3} 5 \times 10^{-3} \mathrm{M}$ indicam que o boro estimulou a absorção do cálcio e diminuiu a velocidade máxima.

$\mathrm{O}$ estímulo da absorção de $\mathrm{K}$ e $\mathrm{Br}$ pelo $\mathrm{Ca}$, foi constatado por VIETS 
(1944) em experimentos com raízes destacadas de cevada. Explica o autor que os cátions polivalentes na presença de $\mathrm{KBr}$ aumentam aparentemente, a velocidade da respiração, a perda de açúcar, a velocidade e a capacidade total de acumulação.

Assim sendo, o tipo de efeito do boro na absorção de cálcio, sugere o vínculo do cálcio a outros pontos de ligação dos carregadores, cuja afinidade é estimulada pela presença de $\mathrm{H}_{3} \mathrm{BO}_{3}$.

\section{CONCLUSÓES}

a. A absorção de cálcio é descrita por um mecanismo único de absorção.

b. A absorção de cálcio é metabólica. cálcio.

c. A presença de $\mathrm{KCl} 10^{-4} \mathrm{M}$ e $5 \times 10^{-3} \mathrm{M}$, estimula a absorção de

d. A presença de $\mathrm{MgCl}_{2} 5 \times 10^{-3} \mathrm{M}$ inibe, não competitivamente, a absorção de cálcio.

e. A presença de $\mathrm{H}_{3} \mathrm{BO}_{3} 5 \times 10^{-3}$ estimula a absorção de cálcio.

\section{SUMMARY}

STUDIES ON CALCIUM ABSORPTION BY COFFEE (COFFEA ARABICA L. VAR. MUNDO NOVO) LEAVES.

Researches were conducted in order to:

a. detect mechanisms involved on the calcium absorption by leaves.

b. calcium uptake as function of potassium, magnesium an boron in the external solution.

The leaf tissued used for experiments came from young coffee trees growing in a Piracicaba grove. The tissue was prepared by cutting it into slices of $300 \mu$ width. Slices after cuted were placed into a large volume of deionized water and rinsed several times to remove ions released from demaged cells. Slices were randomly allocated to batches, and placed to into $500 \mathrm{ml}$ of ${ }^{45} \mathrm{CaCl}_{2}$ labelled areted solution for 60 minutes.

The experimental solutions contained

$5 \times 10^{-6} \mathrm{M}, 10^{-5} \mathrm{M}, 2 \times 10^{-5} \mathrm{M}, 4 \times 10^{-1} \times 10^{-4} \mathrm{M}, 6,4 \times 10^{-4} \mathrm{M}, 1,28 \times 10^{-3} \mathrm{M}$ ${ }^{-5} \mathrm{M}, 8 \times 10^{-5} \mathrm{M}, 1,6 \times 10^{-4} \mathrm{M}, 3,2 \times$ e $2,56 \times 10^{-3} \mathrm{M}$.

concentration of ${ }^{45} \mathrm{CaCl}_{2}$. Experiments were carried out at $30^{\circ} \mathrm{C}$. Light was provided by four 20W fluorescent tubes (3000 lux).

The possible occurence of interactions and mutual competitions in the 
absorption of potassium, magnesium and boron was investigated in a series of experiments. Each solution contained $\mathrm{KCl} 10^{-4}$ and $10^{-3} \mathrm{M}, \mathrm{MgCl}_{2}$ $5 \times 10^{-3} \mathrm{M}$ and $\mathrm{H}_{3} \mathrm{BO}_{3} 5 \times 10^{-3} \mathrm{M}$.

The slices were then removed, blotted, dried at $70^{\circ} \mathrm{C}$, and weighed. The material was ashed at $600^{\circ} \mathrm{C}$, dissolved with $2 \mathrm{ml} \mathrm{HCl} 0,01 \mathrm{~N}$. Aliquot were transferred to planchet, dried, and the radioactivety was assayed.

The data from all experiments were run through statistical estimations (regression analysis and Student's «t-test»).

Calcium influx was reduced and inhibited by DNP, $\mathrm{N}_{2}$ and also by temperature $\left(10^{\circ} \mathrm{C}\right)$.

The theory and terminology of active transport used was the same as applied by Epstein and Hagen (1952) for root tissues.

The concluding comments are:

a. the absorption of calcium is an actif process, involving a single mechanism. absorption.

b. potassium and boron ions induces a stimulatory efect on calcium

c. magnesium ions presents a non competitive inhibition interference on calcium.

\section{LITERATURA CITADA}

BOWEN, J. E. - 1968 - Borate absorption in excised sugar-cane leaves. Pl. Cell. Physiol., 9 : 467-78.

- 1969 - Absorption of copper, zinc and manganese by sugarcane tissue. Plant Physiol., 44 : 255-61.

DUNLOP, J. - 1973 - The kinetcs of calcium uptake by roots. Planta (Berl.), 112 : 159-67.

EPSTEIN, E., HAGEN, C. E. - 1952 - A kinetic study of the absorption of alkali cations by barley roots. Plant Physiol., $27: 457-74$.

EPSTEIN, E., J. E. LEGGETT - 1954 - The absorption of alkaline earth cations by barley roots: kinetics e mechanism. Am. J. Botan., $41: 785-91$.

EPSTEIN, E. - 1966 - Dual pattern of ion absorption by plant cells and by plants. Nature $212: 1324-27$.

HANDLEY, R., R. OVERSTREET - 1961 - Uptake of calcium and chlorine in roots of Zea mays. Plant. Physiol. 36 : 766-69.

JACOBY, B., O. E. PLESSNER - 1970 - Some aspects of chloride absorption by leaf tissue. Ann. Bot. (London) $34: 177-82$.

JOHANSON, L. H. E. JOHAM - 1971 - The influence of calcium absorption and accumulation on the growth of excised cotton roots. Plant and Soil, $34: 331-39$.

JOHNSON, R. E., W. A. JACKSON - 1964 - Calcium uptake and transport by wheat seedlings as affected by aluminium. Soil Sci. Soc. Am. Proc., $28: 381-86$.

MAAS, E. V. - 1969 - Calcium uptake by excised maize roots and interactions with alkali cations. Plant Physiol., $44: 895-89$. 
MOORE, D. P. - 1972 - Mechanisms of micronutrient uptake by plants. In «micronutrients in agriculture» (R. C. DINAUER ed.) Soil Science Society of America, Inc. Wisconsin U. S. A., p. 171-98.

MOORE, D. P., L. JACOBSON e R. OVERSTREET - 1961 - Uptake of calcium by excised barley roots. Plant Physiol., 36 : 53-67.

NISSEN, P. R. - 1971 - Uptake of sulfate by roots and leaf Slices of barley: Mediated by single multiphasic mechanisms. Physiol. Plant 24 : 815-24.

PIMENTEL GOMES, F. - 1963 - Curso de Estatística Experimental. Instituto de Genética E. E. A. «Luiz de Queiroz». Piracicaba - S.P.

RAINZ, D. W. - 1968 - Kinetics and energetics of Light-Enhanced Potassium absorption by carn leaf tissue. Plant Physiol. $43: 394-400$.

ROBINSON, J. B., F. A. F. A. SMITH - 1970 - Chloride influx into citrus leaf slices. Aust. J. Biol. Sci., 23 : 953-60.

SARRUGE, J. R. - 1968 - Estudo sobre as relações cálcio/boro e potássio/boro no cafeeiro. Tese E. S. A. «Luiz de Queiroz», Universidade de São Paulo, Piracicaba - SP. 77 pags. mimeografada.

SCHMID, W. E., H. P. HAAG e E. EPSTEIN - 1965 - Absorption of zinc by excised barley roots. Physiol. Plantarum, $18: 860-69$.

SMITH, R. C., E. EPSTEIN - 1958 - The absorption by shoot tissue: Tecnique and first findings with excised leaf tissue of corn. Plant. Physiol. 39:338-41. Rubidium absorption by corn leaf tissue Plant Physiol. 39 : 992-96.

SMITH, F. A., J. B. ROBINSON - 1971 - Sodium and Potassium influx into citrus leaf slices. Aust. J. Biol. Sci., $24: 861-71$.

VIETS, F. G. - 1944 - Calcium and other polivalent cations as accelerators of ion accumulation by excised barley roots. Plant Physiol., $19: 466-80$.

WAISEL, Y. - 1962 - The effect of $\mathrm{Ca}$ on the uptake of monovalent ions by excised barley roots. Physiol. Plant $15: 709-24$. 